Conclusion So, the pulse-therapy has more considerable antiinflammatory effect comparing to antiplatelet agents and vasodilators, therefore it is necessary to include it in the scheme of therapy pts with thrombangiitis obliterans.

\section{FRI0156 CYTOKINE RESPONSES TO STREPTOCOCCUS SANGUIS IN PATIENTS WITH BEHCET'S DISEASE}

${ }^{1} \mathrm{G}$ Mumcu, ${ }^{2} \mathrm{~T}$ Ergun, ${ }^{3} \mathrm{~N}$ Aritan, ${ }^{4} \mathrm{E}$ Eksioglu-Demiralp, ${ }^{3} \mathrm{H}$ Direskeneli. ${ }^{1}$ Health Education Faculty; ${ }^{2}$ Dermatology; ${ }^{3}$ Rheumatology; ${ }^{4}$ Immunology, Marmara University, Istanbul, Turkey

\subsection{6/annrheumdis-2001.216}

Background Atypical streptococcal infections (Streptoccocus Sanguis, Salivarius) are implicated in the pathogenesis of Behcet's Disease (BD), a systemic vasculitis of unknown aetiology.

Objectives This study aimed to investigate in mononuclear cell culture supernatants, in vitro cytokine responses to S. Sanguis in patients with BD compared to psoriasis (PS) and healthy controls (HC).

Methods Twelve patients with BD (4F/8M, mean age: 33.6 years), 7 with PS (4F/3M, mean age: 38.2 years) and $10 \mathrm{HC}$ (7F/3M, mean age: 27.5 years) were included in the study. IL-4, IL-10, and IFN- $\gamma$ responses were measured in peripheral blood mononuclear cell culture supernatants by ELISA after $48 \mathrm{~h}$ stimulations with S. Sanguis $(10 \mu \mathrm{g} / \mathrm{ml})$ and PHA $(20 \mu \mathrm{g} / \mathrm{ml})$. Positive responses were defined as above mean $+2 S D$ of unstimulated samples from HC.

Results Positive IL-10 responses to S. Sanguis were observed in 5/12 patients with BD (mean: $94 \mathrm{pg} / \mathrm{ml}$ ), 2/7 with PS (76 pg/ml), and $3 / 10$ with $\mathrm{HC}(57 \mathrm{pg} / \mathrm{ml})$. IFN- $\gamma$ responses were prominent both after S. Sanguis (BD: 4/12 positive, $31 \mathrm{pg} / \mathrm{ml}$; PS: 1/7 positive, $19 \mathrm{pg} / \mathrm{ml}$; HC: $1 / 10$ positive, $19 \mathrm{pg} / \mathrm{ml}$ ) and PHA (BD: 4/12 positive, $493 \mathrm{pg} / \mathrm{ml}$; PS: $1 / 7$ positive, $47 \mathrm{pg} / \mathrm{ml}$; HC: 0/10 positive, $10 \mathrm{pg} / \mathrm{ml}$ ). No IL-4 responses were observed in any group against both antigens.

Conclusion Although Th1 type cytokine responses are generally accepted to be dominant in $\mathrm{BD}$, in addition to IFN- $\gamma$, a prominent IL-10 response against S. Sanguis is observed in this study. These results suggest that a more complex cytokine profile is present in BD against microbial antigens.

\section{FRI0157 ANCA ANTIBODIES IN GRAVE'S BASEDOW DISEASE}

${ }^{1} \mathrm{M}$ Gumà, ${ }^{2} \mathrm{M}$ Juan, ${ }^{3} \mathrm{I}$ Salinas, ${ }^{1} \mathrm{E}$ Casado, ${ }^{1} \mathrm{~V}$ Ortiz-Santamaría, 'A Olivé. ${ }^{1}$ Rheumatology; ${ }^{2}$ Immunology, Hospital Universitari Germans Trias I Pujol, Badalona, Spain; ${ }^{3}$ Endocrinology

\subsection{6/annrheumdis-2001.217}

Background ANCA (anti-neutrophil cytoplasmic antibodies) are antibodies against specific proteins (proteinasa 3 and myeloperoxidase) and are present in the sera of patients having several underlying diseases).

Objectives To determine the frequency and specificity of ANCA in Grave's disease.

Methods Thirty-five serum of patients with Grave's Basedow disease were retrospectively examined. All patients were on treatment with anti-thyroid drugs at least for two months. ANCA antibodies were determined by indirect immunofluorescence. A ELISA test was performed to examine the presence of proteinasa 3 and myeolperoxidase (BL Diagnostica).

Results ANCA were positive in 60\% of patients with Grave's Basedow disease. Immunofluorescence patterns were as follow: 9
pANCA (26\%), 7 xANCA (20\%) and 5 cANCA (14\%). ELISA was positive in just one case (myeloperoxidase).

Conclusion ANCA antibodies are positive in Grave's Basedow disease. Anti-thyroid drugs may have a relationship with the presence of ANCA. Antigens are unknow.

\section{FRI0158 MICROSCOPIC HEMATURIA IN TEMPORAL ARTERITIS}

SM Vanderschueren, I Depoot, DC Knockaert, H Bobbaers. General Internal Medicine, University Hospital Gasthuisberg, Leuven, Belgium

\subsection{6/annrheumdis-2001.218}

Background Temporal arteritis (TA) is traditionally considered to spare the kidney, although an uncontrolled study reported microscopic hematuria in 10 out of 30 patients with TA. ${ }^{1}$

Objectives To study the incidence and characteristics of microscopic hematuria in TA.

Methods We studied retrospectively 41 patients with biopsyproved TA (the TA-patients), 41 patients with polymyalgia rheumatica (the PMR-patients) and 43 patients over 65 years of age admitted to the general internal medicine unit (the control patients). Urinalysis and urine microscopy were performed. Microscopic hematuria was defined as the presence of more than 5 red blood cells (RBCs) per high-power field. Patients with pyuria, significant bacteriuria or known urologic or nephrologic disorders were excluded.

Results Heem (trace or more) in the urine was present in $41.0 \%$ patients of the AT-patients, versus in $22.2 \%$ of the PMR-patients $(\mathrm{p}=0.14)$ and in $21.4 \%$ of the control patients $(\mathrm{p}=0.095)$. Microscopic hematuria was significantly more frequent in the AT-patients (Table 1). Presenting symptoms, renal function, arterial blood pressures, degree of proteinuria and of leucocyturia did not differ between AT-patients with and without microscopic hematuria. Urinary RBCs were predominantly dysmorphic in all 7 AT-patients in whom RBC-morphology was assessed. In 2 patients RBC-casts were present. Biopsy in one of them confirmed renal vasculitis. In $69.2 \%$ of the AT-patients microscopic hematuria disappeared after initiation of corticosteroid therapy.

\begin{tabular}{|c|c|c|c|c|}
\hline & -5 & 6-11 & $>11$ & $\mathbf{p}^{*}$ \\
\hline AT-patients & 60.0 & 12.5 & 27.5 & - \\
\hline PMR-patients & 83.0 & 12.2 & 4.9 & .027 \\
\hline Control patients & 88.1 & 4.8 & 7.1 & .001 \\
\hline
\end{tabular}

${ }^{*}$ versus the AT-patients by Pearson chi-square.

Conclusion Microscopic hematuria of renal origin in TA is frequent but generally benign. Its presence, if unassociated with blood pressure elevation or renal function deterioration, serves to rule in rather than rule out the diagnosis of TA. In the typical setting invasive urologic and nephrologic work-up is not warranted.

\section{REFERENCE}

1 Manna R, Cristiano G, Todaro L, Latteri M, Gasbarinni G. Microscopic hematuria: a diagnostic aid in giant-cell arteritis? Lancet 1997;350:1226 